\title{
Research Study of the Problems of Human Resourcing of the Scientific and Innovation Entrepreneurship
}

\author{
Mykola Kyzym, Viktoriia Khaustova, Olena Reshetnyak, Galina Timohova, Oksana Sakhnenko
}

\begin{abstract}
Problems of human resourcing of development of the scientific and innovation entrepreneurship are very urgent especially for the countries, which require a transition from the resource-based economic model to the model of innovation development. That is why, studies of the problems of human resourcing with respect to creation of own scientific developments, science-intensive and innovative products and also a possibility of their commercialization in the domestic entrepreneurial sector is very urgent not only for Ukraine but also for other countries, which are interested in ensuring their competitiveness. The goal of the article is a study of the problems of human resourcing of development of the scientific and innovation entrepreneurship with the help of the cognitive modelling. The paper offers a methodical approach to the study of the human resourcing of development of the scientific and innovation entrepreneurship based on the use of the cognitive modelling. Factors of development of the human resourcing of scientific and innovation processes in the sphere of entrepreneurship of Ukraine have been studied and directions of their reformation have been justified on the basis of the developed cognitive model.
\end{abstract}

Key worlds: human resourcing, scientific and innovation entrepreneurship, cognitive model.

\section{INTRODUCTION}

Scientific knowledge and innovations, which are realized in the entrepreneurial activity, have been the key drive of economic development during the past decades. As the world experience shows, the countries, which do not ensure development of the scientific and innovation entrepreneurship, quickly lose their competitiveness in the global environment. Namely, that is why, the problems of ensuring development of the scientific and innovation entrepreneurship, under which we understand a possibility of creation and commercialization of scientific knowledge and products, are extremely urgent for the majority of the countries of the world independent of their levels of development.

Revised Version Manuscript Received on October 15, 2019.

Mykola Kyzym, Director, Research Centre for Industrial Problems of Development of the Nattional Academy of Sciences of Ukraine, Kharkiv, Ukraine. (Email: ndc_ipr@ukr.net)

Viktoriia Khaustova, Section for Industrial Policy and Innovative Development, Research Centre for Industrial Problems of Development of the National Academy of Sciences of Ukraine, Kharkiv, Ukraine. (Email: v.khaust@gmail.com)

Elena Reshetnyak, Department of International E-Commerce and Hotel and Restaurant Business of V. N. Karazin Kharkiv National University, Kharkiv, Ukraine. (Email: olena.reshetnyak@karazin.ua)

Galina Timohova, Department of Business Administration, Kharkov University of Humanities People's Ukrainian Academy, Kharkiv, Ukraine. (Email: tymohova@gmail.com)

Oksana Sakhnenko, National Academy of the National Guard of Ukraine, Kharkiv, (E-mail: Sakhnenko_Oksana@ukr.net)
Scientific and innovation entrepreneurship is the basis of the modern economy. At the same time, ability of entrepreneurs to implement technologies of transformation of scientific developments into commercially successful commodities/services is the key issue in this transformation process. Many problems, which are connected with human resourcing of the development of scientific and innovation entrepreneurship, arise in view of this and ability of scientists to create such knowledge and results, which would be implemented and commercialized in the future. Readiness of the entrepreneurial sector to pass from the resource-based model of economic development to the innovative one depends on how the state stimulates formation of its own scientific and innovation human resource potential.

One of the key indicators of scientific and innovation development of the countries of the world is human resourcing. According to the World Bank [1], the share of scientists in the whole population gradually increases: from $0.1 \%$ in 1995 up to $0.15 \%$ in 2015 . At the same time, the share of scientists compared to the whole population in Ukraine decreased from $0.22 \%$ in 1995 down to $0.11 \%$ in 2017. According to the studies, the countries with high GDP per capita, which are leaders of the scientific and innovation development, have a bigger share of scientists in the overall population of a country than countries with a low GDP per capita. Thus, the share of scientists in 2018 in the US population was about $0.43 \%$ (GDP per capita - USD 62,605), German population - $0.47 \%$ (GDP per capita - USD 48,264) and Ukrainian population - $0.11 \%$ (GDP per capita - 2,963) [1].

\section{LITERATURE REVIEW}

As regards the human resourcing components of transition to the innovative model of economic development, they include personnel that carries out scientific and research developments; personnel that implements scientific and research developments and research and design operations; personnel that manages the process of implementation of scientific results at enterprises; and personnel that carries out manufacture of science-intensive and innovative products. It should be mentioned that each of the above listed components of human resourcing of the scientific and innovation development is responsible for solving field-specific scientific tasks and requires a separate study of 
the problems, which are connected with their preparation and qualification development, however, it is also possible to specify general problems, which are inherent in all components of human resourcing of the scientific and innovation entrepreneurship.

Studies of human resourcing of the scientific and innovation development are carried out by many scientists in the world, namely: P.D. Aligica and B. Florian [2], D.B. Audretsch and A.R. Thurik [3], W.J. Baumol [4], L.J. Beaulieu and A. Barefield [5], G.M. Bubou, W.O. Siyanbola, [6] and others. However, the complex nature of this range of problems and its weak structuredness require a further study of the factors of influence and tendencies, which were established in the world with respect to human resourcing of scientific and innovation development and application of flexible approaches. Complex and weakly structured problems could be studied with the use of a cognitive model.

Cognitive modelling of complex social and economic problems is considered in the works of such scientists as Z Avdeeva [7], L. Ginis, G. Gorelova [8], M. Kyzym [9] and others. However, a study of problems of human resourcing of the development of the scientific and innovation entrepreneurship with the use of a cognitive approach hasn't been carried out yet.

The goal of the article is a study of problems of human resourcing of the development of the scientific and innovation entrepreneurship with the help of the cognitive modeling/

\section{RESEARCH METHODOLOGY}

Analysis of the existing theory and practice of the problem diagnosing allowed to confirm expediency of the use of functional cognitive maps for presentation of knowledge about development of problem situations with the aim of formal analysis of structural and dynamic specific features of human resourcing of the scientific and innovation entrepreneurship [7]-[9]. This allowed forming a methodical approach of justification of the problems of human resourcing of the scientific and innovation entrepreneurship, the structural scheme of which is shown in Fig. 1

\section{Studying the research object}

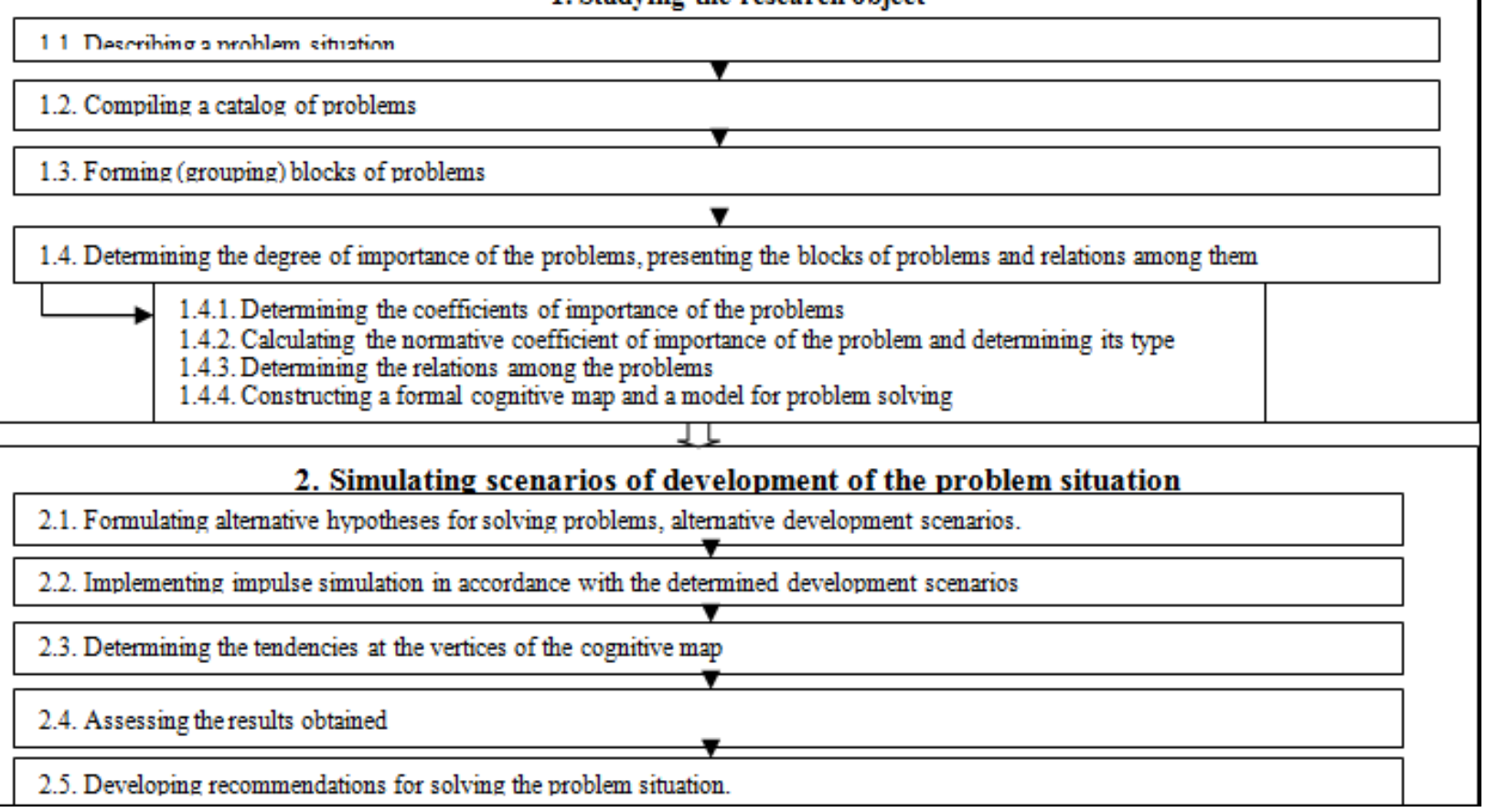

Fig. 1. Structural scheme of a methodical approach of the study of problems of the human resourcing of the scientific and innovation entrepreneurship

The developed methodical approach is based on the structuring of the knowledge about human resourcing of the scientific and innovation entrepreneurship of a country in the form of a symbolic (primary) cognitive map and further selection of a respective functional map [9] depending on specific features and characteristics, which are inherent in the studied situation (problem) and the set formal goals. Let's consider the methodical approach of the study of human resourcing of the scientific and innovation entrepreneurship in the countries of the world in more detail.

Stage 1 . The study of the object of research.

1.1. Description of the problem situation. When describing problem situations in the human resourcing of the scientific and innovation entrepreneurship, it is necessary to identify the whole range of knowledge about the needs and availability of the scientific personnel, its formation, financing, etc.

1.2. Composition of the problem catalogue. The formed image of the problem situation and also analysis of tendencies of statistical indicators, which confirm it, provide a possibility to compose a list of problems, which have to be solved for achieving the goal of development of the scientific and innovation entrepreneurship. 
1.3. Formation of the problem blocks. After formation of a complete list of problems, it is necessary to remove those problems, which are insignificant or formulated differently in the same list. In addition, in order to simplify establishment of connections between problems and their visual expression, the problems are grouped in problem blocks by the criterion of similarity in achieving the goal of human resourcing of development of the scientific and innovation entrepreneurship.

1.4. Identification of the degree of significance of the problem. Based on the expert questioning and problem comparing, cause-and-effect connections are established between them, which allows building the primary cognitive map.

The paper offers to use the functional cognitive map, which has the following features: allowability of a structural analysis of integral mutual influence between the problems; expressiveness of the managerial influence; and identification of the rules of variables, which allows map modelling without cycles. The formal linear $\mathrm{K}_{\mathrm{F}}$ map is set by a number of factors (problems) $X=\left\{x_{1}, \ldots, X_{n}\right\}$ and a number of $\mathrm{X}_{\mathrm{I}}$ straights of the cause-and-effect influences of factors (problems) upon the factors. The model of the map of this type identifies a respective influence weight (positive or negative) - matrix $\mathrm{N}$, and also a degree of this influence. The degree of the influence weight of the factor (problem) ' $i$ ' on factor ' $\mathrm{j}$ ' $\left(\mathrm{a}_{\mathrm{ij}}\right)$ is identified on the basis of the linguistic scale of assessment of the connection of the following types: very weak connection (0.119), weak connection (0.309), medium connection (0.618) and strong connection (0.942). Assessments of mutual influence of the cause-and-effect factors are presented in the form of the matrix A with dimensions $n \times n$.

Identification of the significance ratios of the problems of significance of the ' $\mathrm{j}$ ' factor in accordance with its influence on the ' $i$ ' factor $-1_{j i}$ is carried out by an expert method for the problems of one level based on the Saaty hierarchy process. To do it we will compare the problems among themselves with respect to the problem they influence. The problem type is identified on the basis of calculation of ratios of the problem significance in the problem block.

Thus, we can formulate the model of the study of problems of human resourcing of the scientific and innovation entrepreneurship, which includes a set of parameters:

(1)

$$
M_{S}=<K_{F}\left(X=\left(X_{\text {int }} \cup X_{\text {int }}\right), A, L, N, f_{K_{F}}\right) ; C\left(X^{C}, R\left(X^{C}\right)\right) ; X(0) ; U>
$$

where $\mathrm{F}_{f}-$ is a cognitive map, which characterizes development of the scientific and innovation entrepreneurship in a country, A - is a matrix of values of the ratios of the cause-and-effect influence of factor ' $j$ ' upon factor ' $i$ '; $L$ - is a matrix of values of ratios of the problem significance; $\mathrm{N}$ - is a matrix, which characterizes influence of one problem upon another (its direction is positive or negative), $\mathrm{C}$ - is a target image, $\mathrm{X}(0)$ - is a vector of initial values of the problems of human resourcing of the scientific and innovation entrepreneurship, $\mathrm{X}_{\mathrm{int}}$ - are indices of factors of internal and external environment, which characterize the problem; $\mathrm{U}$ - is a vector of control influences (supply of external $U$ influences on the map factors is allowed (unconditioned by direct influences from adjacent factors, which are set in the scale $[-1,1]$ with a respective linguistic value of the influence character - negative or positive).

Stage 2. Modelling scenarios of development of a problem situation.

2.1. Formulation of alternative hypotheses for solving the problems and alternative development scenarios. Hypotheses of development of problem situations under influence of different controlled factors are formulated at this stage on the basis of the whole mass of information about specific features of the system and its state.

2.2. Realization of the impulse modelling with the use of the identified development scenarios. Impulse modelling of possible scenarios of the system development (in this study science in Ukraine) for solution of the identified problems is carried out for building a cognitive map and justification of possible directions of development. Impulse values at vertices of the cognitive map with a time step ' $n$ ' of modelling are determined by the following formula:

$$
c_{V i}(n+1)=c_{V i}(n)+\sum_{v_{j}, e=e_{0 i j} \in E}^{k=1} f\left(x_{i}, x_{j}, f_{i j}\right) P_{j}(n)+U_{V i}(n),
$$

where $c_{v i}(n)$ and $c_{v i}(n+1)$ are impulse values at xi vertex at time stages of modelling $n$ and $(n+1)$ of the target image; $f_{i j}=l_{i j} \times a_{i j}-$ is a function of connection between the vertices $x_{j}$ and $x_{i} ; P_{j}(n)$ - are impulses at vertices $x_{j}$, which adjoin $x_{i} ; U_{v i}(n)$ - is a vector of perturbations introduced at the vertex.

The impulse process may reflect both evolution development of the system $(U=0)$ and its development under influence of violations and controlling influences $U_{v i}$ $(n)$, which are introduced into vertex vxi at the moment of tn. The totality of realizations of impulse processes is the 'development scenario', which points to possible tendencies of the situation development. In the event of the impulse modelling, a situation is characterized with a set of all $U$ and $\mathrm{C}$ values at each time step of modelling.

2.3. Identification of tendencies at vertices of the cognitive map. A tendency at each vertex of the cognitive map is determined by the formula (2).

2.4. Assessment of the obtained results. It is assessed at this stage whether the target values were achieved. If so, the problem is solved. If target values haven't been achieved, the problem is not solved and it is necessary to justify the direction of the problem solution. In this case, the problem situation could be presented as follows:

$$
P_{i}^{*}=\left\{\begin{array}{l}
o_{i}, \text { if } o_{i}<0 \in I_{\mathrm{int}} \\
0, \text { if } o_{i}>0 \text { or } i \notin I_{\mathrm{int}}
\end{array},\right.
$$

$P_{i}^{*}$ - is a vector of assessment of the goal achievement.

In such a way, identification of problem factors at this stage is carried out on the basis of assessment of the focused development of the economic system within the formed display of the goal and initial stage of the if step, which allows specification of a problem situation in development of the economic system in the form of the $P_{i}{ }^{*}$ vector and problem factors, the change of which doesn't correspond with the target image. 
2.5. Development of recommendations with respect to solution of a problem situation. Recommendations with respect to improvement of the current situation are formed on the basis of the results of the study of problems of human resourcing of the scientific and innovation development in the result of modelling of the cognitive map and assessment of scenarios of influence of the control factors.

\section{RESULT AND DISCUSSION}

In accordance with the proposed structural scheme of the

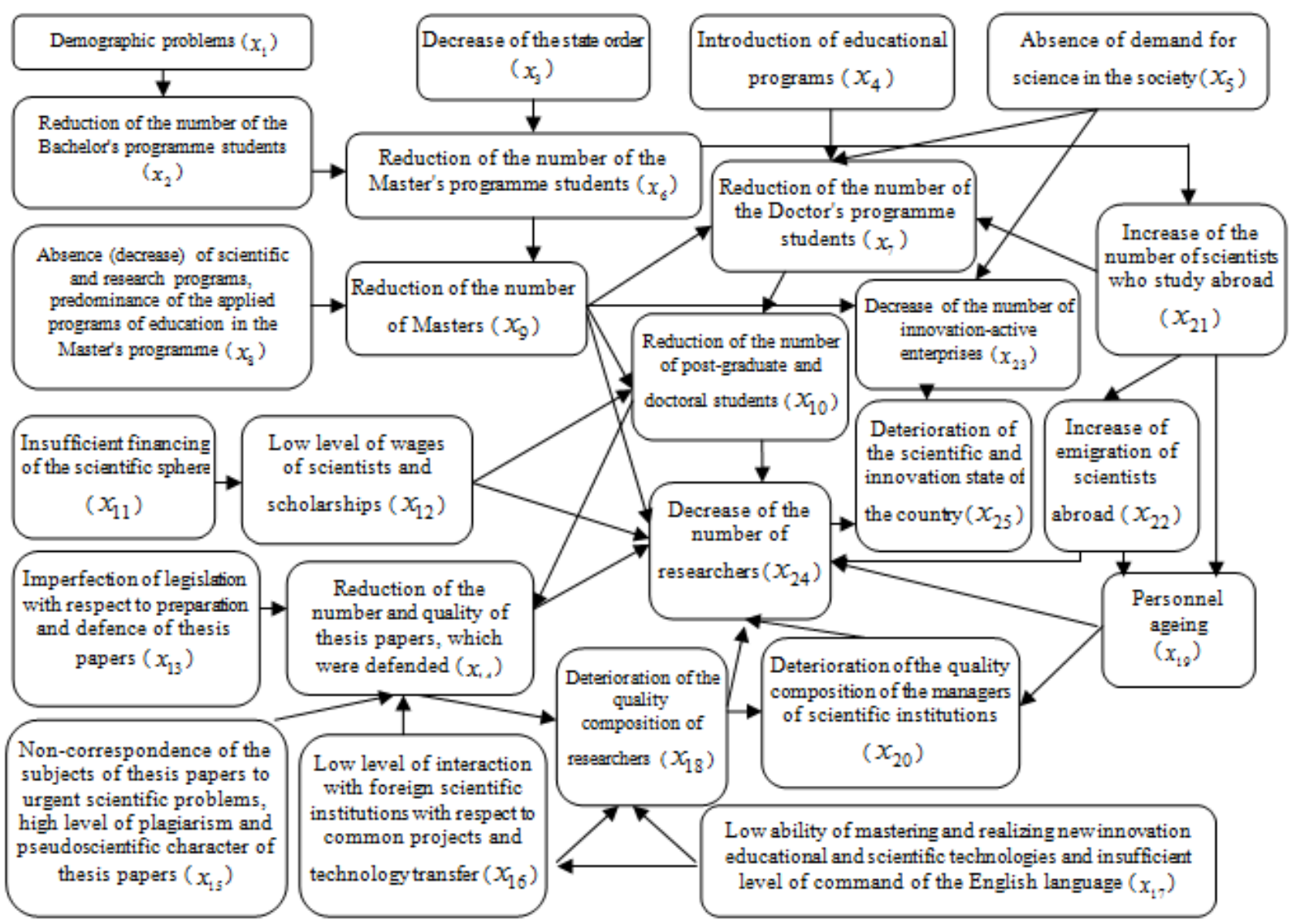

Fig. 2. Primary cognitive map of the study of human resourcing of the scientific and innovation entrepreneurship Source: Own research

In the result of the further analysis we assessed significance of problems and their mutual influence, calculated ratios of significance of each problem in the problem group (A matrix), identified the degree of interconnection of the problems ( $\mathrm{L}$ matrix) and their focus $(\mathrm{N}$ matrix) in accordance with the offered methodology (see Fig. 1). A cognitive model of the study of human resourcing of development of the scientific and innovation entrepreneurship, which is shown in Fig. 3, was built on the basis of the conducted calculations.

Impulse modelling of the influence through the example of the use of the offered cognitive model for various scenarios of managing the staff potential was carried out at the next stage. Managerial influences could be applied to all root vertices of the model depending on the selected directions of reformation. The control influences (impulses) could be applied separately to all root vertices of the cognitive model or form a complex of control influences in accordance to which it is possible to analyze the aggregate of scenarios of development of the problem field by the formed cognitive methodic approach to the study of problems of human resourcing of the scientific and innovation entrepreneurship (see Fig. 1), the field of existing problems in this sphere was formed and they were analyzed with consideration of the world experience in human resourcing of the scientific and innovation entrepreneurship, those of them were specified, which are the most important ones, main indicators of their assessment were selected [10] and the primary cognitive chart, which is shown in Fig. 2, was built. 
enterprises and also scientists who would develop innovation products for the domestic economy. The way of the impulse process for perturbation (impulse) U1 is marked in Fig. 2. Scenario 2: the control influence is an increase of financing of the scientific sphere, which was received at applying of the perturbation in the $x_{11}$ vertex, value $\mathrm{U} 2=+1$. Perturbation (impulse) U2 models a hypothesis that, in the event of increase of financing of the scientific sphere and increase of the wages of scientists and also increase of scholarships of post-graduate and doctoral students, we may expect a gradual increase of the number of researchers who would be able to develop scientific and innovation products for the Ukrainian economy. Scenario 3: the control influences of increase of the state order in the Master's programme (U1) and increase of financing of the scientific sphere (U2) are applied altogether. Perturbation (impulse) $U=\{+1,+1\}$ models a hypothesis that an increase of the number of researchers and growth of their wages would result in improvement of the scientific and innovation state of the country.

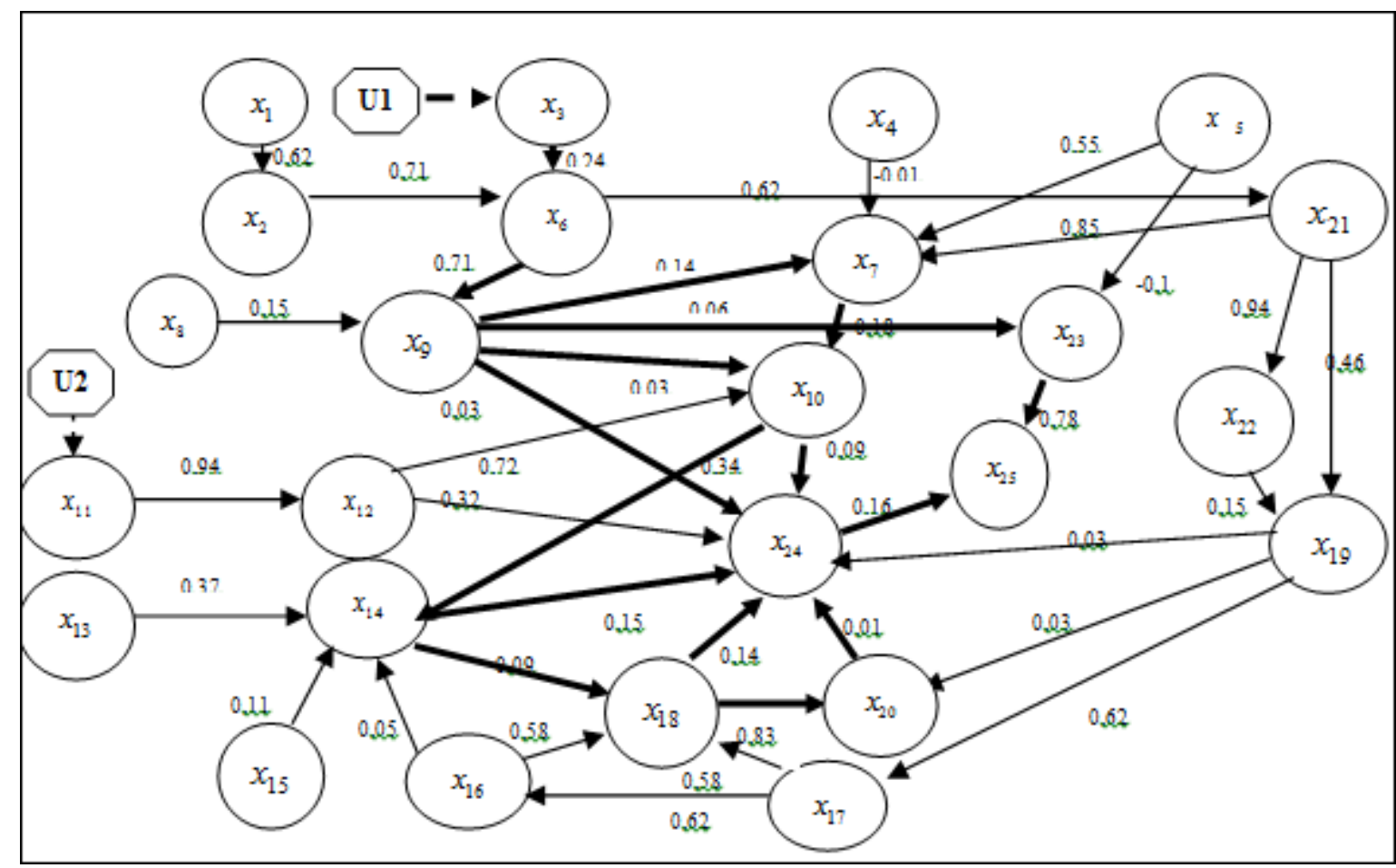

Fig. 3. A cognitive model of the study of human resourcing of development of the scientific and innovation entrepreneurship

Source: Own research.

Influence of impulses by the formula (2) is determined in accordance with the proposed hypotheses. The tendencies at the vertices of the cognitive map were identified in accordance with the calculation experiments by the formed scenario (see Table I). It was identified that, in accordance with the conducted calculations and analysis of scenarios of the control influences and tendencies, which are observed in the factors of human resourcing of development of the scientific and innovation entrepreneurship in Ukraine, identified on the basis of the cognitive model of existing problems, a complex introduction of several directions of reformation is the most efficient at this stage of economic development of the country.

Table I- Tendencies in accordance with the impulse influence modelling scenarios

\begin{tabular}{|c|c|c|c|c|c|c|c|c|c|c|c|c|c|}
\hline Scenario & $x_{3}$ & $x_{6}$ & $x_{7}$ & $x_{9}$ & $x_{10}$ & $x_{11}$ & $x_{12}$ & $x_{14}$ & $x_{18}$ & $x_{20}$ & $x_{23}$ & $x_{24}$ & $\begin{array}{c}\text { Expected improvement of the } \\
\text { scientific and innovation } \\
\text { development }\left(x_{25}\right)\end{array}$ \\
\hline $\mathbf{1}$ & - & $\mathbf{3}$ & $\mathbf{3}$ & $\mathbf{3}$ & $\mathbf{3}$ & $\mathbf{1}$ & $\mathbf{1}$ & $\mathbf{3}$ & $\mathbf{3}$ & $\mathbf{3}$ & $\mathbf{3}$ & $\mathbf{3}$ & $\mathbf{3}$ \\
\hline $\mathbf{2}$ & $\mathbf{1}$ & $\mathbf{1}$ & $\mathbf{1}$ & $\mathbf{1}$ & $\mathbf{4}$ & - & $\mathbf{4}$ & $\mathbf{1}$ & $\mathbf{1}$ & $\mathbf{1}$ & $\mathbf{1}$ & $\mathbf{4}$ & $\mathbf{4}$ \\
\hline $\mathbf{3}$ & $\mathbf{1}$ & $\mathbf{3}$ & $\mathbf{3}$ & $\mathbf{3}$ & $\mathbf{4}$ & $\mathbf{1}$ & $\mathbf{4}$ & $\mathbf{3}$ & $\mathbf{3}$ & $\mathbf{3}$ & $\mathbf{3}$ & $\mathbf{4}$ & $\mathbf{4}$ \\
\hline
\end{tabular}

Identification of the problem factors on the basis of assessment of the focused development of the scientific and innovation entrepreneurship within the framework of the formed target image in accordance with the formula (3) is carried out after analysis of the received scenarios. Thus, it is possible to study the factors of development of human resourcing of scientific and innovation processes in the sphere of entrepreneurship and justify directions of their reformation on the basis of the proposed cognitive model. 


\section{CONCLUSION}

The modern dissemination of scientific knowledge and innovations, which are the basis for building the innovation model of economic development, have increased requirements to their human resourcing. It was identified that the number of researchers who create scientific knowledge and innovation products have an influence on the state of economy, which is characterized with the GDP per capita level. Namely, that is why, it is necessary to form the country's own scientific potential for ensuring competitiveness and sustained development. It is very important for the countries, which are behind the leaders of innovation development, to study the problems of human resourcing of the scientific and innovation entrepreneurship. The paper offers a methodical approach on the basis of the cognitive modelling, which allows to explore main problems of development of the scientific and innovation entrepreneurship with consideration of the problems of its human resourcing. The developed cognitive model, as well as the study of scenarios of development of the scientific and innovation entrepreneurship on the basis of the impulse modelling, allowed to justify a necessity of introduction of a complex approach of reformation of the system of training scientific personnel and also increase of financing of the scientific activity

\section{REFERENCES}

1. World Bank. World Development Report 2019: The Changing Nature of Work. World Development Report; Washington, DC: World Bank. 2019. Available: https://openknowledge.worldbank.org/handle/10986/304 35

2. P.D. Aligica and B. Florian, "Entrepreneurship and Education. The missing Link in International Development Theory and Practice," Int. J. Business and Globalisation, 2008, vol. 2, no. 1, pp. 28-38.

3. D.B. Audretsch and A.R. Thurik, "A Model of the Entrepreneurial Economy," Int. J. Entrepreneurship Education, 2004, vol. 2, no. 2, pp. 143-66.

4. W.J. Baumol, "Entrepreneurship: Productive, Unproductive, and Destructive," J. Political Economy, 1990, vol. 98, no. 5, pp. 893-921.

5. L.J. Beaulieu and A. Barefield, "The Voices of the People: Strategies for Expanding Entrepreneurship in the Rural South". Southern Rural Development Centre, Barbara Ray, HiredPen, Inc, 2006.

6. G.M. Bubou, W.O. Siyanbola, M.C. Ekperiware, S. Gumus, "Science and technology entrepreneurship for economic development in Africa (SEEDA)". International Journal of Scientific and Engineering Research. 2014, vol 5(3), pp. 921-927

7. Z. Avdeeva, S. Kovriga, "The technology of the strategic goal-setting and monitoring of a system development on the basis of cognitive mapping". Procedia Computer Science, 2017

8. L. Ginis, G. Gorelova, A. Kolodenkova, "Cognitive and simulation modeling of development of regional economy system". International Journal of Economics and Financial Issues. 2016, vol 6, No 5S, - p. 97- 103.

9. M. Kyzym, O. Reshetniak and O. Lelyuk "Simulating Development of Science in a Country with the Use of the Cognitive Approach". SHS Web Conf., 67, 2019. 01008. Available:

DOI: https://doi.org/10.1051/shsconf/20196701008

10. The State Statistics Service of Ukraine [online]. 2019. Available: www.ukrstat.gov.ua/ 